Témoigner Témoigner. Entre histoire et mémoire

Getuigen Revue pluridisciplinaire de la Fondation Auschwitz

125 | 2017

Histoire et mémoire de la persécution des

homosexuel-le's par les nazis

\title{
Mémoire d'État et état de la mémoire
}

Staats-herinnering en staat van de herinnering

\section{Frédéric Crahay}

\section{(2) OpenEdition}

12 Journals

Édition électronique

URL : https://journals.openedition.org/temoigner/6005

DOI : 10.4000/temoigner.6005

ISSN : 2506-6390

Traduction(s) :

Staats-herinnering en staat van de herinnering - URL : https://journals.openedition.org/temoigner/ 6009 [nl]

Éditeur :

Éditions du Centre d'études et de documentation Mémoire d'Auschwitz, Éditions Kimé

Édition imprimée

Date de publication : 1 octobre 2017

Pagination : 4

ISBN : 978-2-930953-01-4

ISSN : 2031-4183

\section{Référence électronique}

Frédéric Crahay, « Mémoire d'État et état de la mémoire », Témoigner. Entre histoire et mémoire [En ligne], 125 | 2017, mis en ligne le 24 décembre 2021, consulté le 04 février 2022. URL : http:// journals.openedition.org/temoigner/6005; DOI : https://doi.org/10.4000/temoigner.6005 
$\rightarrow$ Par Frédéric Crahay,

Directeur de la rédaction

Mémoire d'État et état de la mémoire

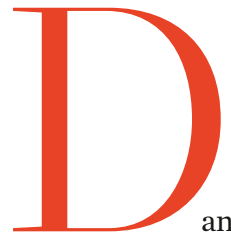

ans notre éditorial d'avril 2017, nous évoquions les problèmes que rencontre le musée de la Seconde Guerre mondiale à Gdansk face à la politique du gouvernement polonais. Depuis son inauguration en janvier dernier et son ouverture au public depuis mars, le musée est dans le collimateur du ministre de la Culture du parti Droit et Justice, Piotr Gliński. Ce dernier avait refusé l'invitation à l'inauguration du nouveau musée, ce qui jeta encore plus un froid dans une situation déjà tendue. Ainsi, la scénographie de l'exposition permanente ne flatterait pas assez l'esprit d'héroïsme et le sacrifice de la nation polonaise et serait trop européenne. Bien que l'exposition soit encore en place à l'heure où nous écrivons ces lignes, le directeur du musée, le professeur Paweł Machcewicz a lui bel et bien perdu son poste. Cet historien de l'Université de Varsovie est venu en Belgique en mai 2017 pour faire écho des pressions qu'il a dû subir. Dans une interview accordée au journal Le Soir du 3 juin 2017, il explique qu’elles ont commencé dès 2008 , depuis le début du projet muséal. Le parlement polonais avait évoqué des critiques contre la participation d'un large panel d'historiens spécialistes en la matière, leur défaut étant de ne pas tous être polonais. Une autre remarque, également inquiétante de la part d'un parlement censé représenter la démocratie, était que le musée se préoccupait trop du sort des civils. Faut-il rappeler que la grande majorité des victimes de la Seconde Guerre mondiale étaient justement des civils et que c'est aussi en ce sens qu'elle n'a pas été une guerre comme les autres? Cela laisse matière à réflexion pour le futur du musée dont le nouveau directeur, Karol Nawrocki qui a été désigné le 6 avril 2017, a déjà annoncé vouloir changer le contenu et surtout la façon dont celui-ci est présenté au public. Pourtant, le public polonais a bien répondu présent lors des premiers mois d'ouverture de l'exposition. Les réactions des visiteurs sont enthousiasmantes pour les concepteurs du projet initial. Les historiens polonais ne sont d'autre part pas en reste. Une lettre de soutien au musée actuel a été signée par une centaine d'entre eux. Sera-ce toutefois suffisant pour éviter une grossière réécriture de l'Histoire?

Dans un autre registre, en Belgique, nous commémorons les 75 ans du début des déportations de civils juifs depuis la caserne Dossin à Malines vers le centre d'extermination d'Auschwitz-Birkenau. Les rafles de l'été1942 à Anvers et Bruxelles méritent aussi une attention particulière dans ce sens. Pour rappel, 25528 furent déportés entre 1942 et 1944 en 28 convois (dont un convoi de 354 Tsiganes), environ 1251 en sont revenus. Les convois de trains sont devenus depuis un symbole de la déportation vers la mort. Le lieu emblématique de cette déportation qu'est le sous-sol de la caserne Dossin à Malines et où se trouve l'actuel mémorial verra son aspect modifié dans l'année qui suit. Le but étant, a contrario de ce qui pourrait se passer à Gdansk, de le rendre plus humain et moins «froid». Le lieu d'histoire et de mémoire qu'est la caserne Dossin vient de voir paraitre son ouvrage de référence avec la publication du docteur Laurence Schram Dossin, L'antichambre d'Auschwitz, publié par Racine en juin dernier. En lisant les nombreux témoignages des rescapés qui constituent son récit, la commémoration des déportations depuis la Belgique en gagnera forcément en humanité. 